\title{
The Impact of Cloud Computing Technology on Organizational Performance; Financial, Customer, Operational (Case Study: Zarin Iran Porcelain Industries Co.)
}

\author{
Sonia Mirrazavi \\ Master of Technology Management, Department of Technology Management, Faculty of Management And Accounting, \\ Tehran South Branch, Islamic Azad University, Tehran, Iran \\ Email: SoniaMirrazavi@gmail.com

\section{*P.h.D Gholamreza Hashemzadeh Khoorasgani} \\ Assistant Professor, Department of Technology Management, Faculty of Management And Accounting, \\ Tehran South Branch, Islamic Azad University, Tehran, Iran \\ Email: Gh_hashemzadeh@azad.ac.ir
}

Doi:10.5901/mjss.2016.v7n4s1p279

\begin{abstract}
Cloud computing can be referred as using the capabilities of computers based on the Internet. These capabilities such as software, information and shared computing resources can be offered to clients as a web-based Internet service. Thus, storing and processing online information are done by numerous powerful servers on the Web and its result is offered to the customer. The cloud is just a metaphor for the Internet and a series of nested and wide web networks. Its point of similarity is that the technical details and computing technology are hidden for user. This study aims at investigating the impact of cloud computing technology on the performance of Zarin porcelain Industries Company. Population of this study consists of Zarin Iran porcelain Industries Company's experts which it was 80 persons. The sample size was calculated 66 persons according to the Morgan's sampling table and questionnaires have been distributed among them. Data are analyzed by using SPSS software. Results showed that cloud computing technology has a positive and significant impact on the organizational performance. Also, cloud computing has a positive and significant impact on the dimensions of organizational performance- financial, customer and operational.
\end{abstract}

Keywords: Cloud computing technology, Organization performance

\section{Introduction}

Cloud computing means development and use of Internet-based computer technology. This includes the ways of computer calculations in a space that IT-related capabilities are offered to user as services and it allows him to access the Internet-based services without having specialized information about these technologies or needs to control the technology infrastructures that supports them $\left(\mathrm{NIST}^{1}, 2015\right)$. Cloud computing is focused on providing the services which it is requested by users as a service. CDCs ${ }^{2}$ as providers of users' requested services focused on the procurement and management of systems' hardware and software needed for service in order to provide optimal services and maintain the quality of requested services. This serving is such that user can enjoy more desirable and appropriate service by paying more expenses. Through this emerging technology's approach, the world of computing moves quickly to a direction that applicants tend to get services from cloud providers instead of doing works and getting required services locally. So, cloud computing is a way to increase capacity, or to do it dynamically without investing in new infrastructure. It is also training a new person or authorizing new software. Because it assigns the necessary measures and solutions for cloud providers rather than focus on providing appropriate local solutions for the mentioned issues. Also, organization will prevent from continuity in providing solutions for mentioned issues significantly if the organization itself be a cloud provider (Barnett, 2010). To clarify the concept of emerging cloud technology, cloud providers are analogized to electricity generation plants and the applicants for services are also analogized to home users that their electrical appliances need to work on electric power. Certainly, there is no power plant or generator for use of electrical appliances in every home

\footnotetext{
${ }^{1}$ National Institute of Standards and Technology

2 Cloud data centers
} 
and there is only on power administration or manufacturer plant and individuals will enjoy the benefits of generated electricity by paying a fee. Similar example can be seen in cloud computing, meaning that individuals and organization do not pay any money for needed network platform, software or hardware to localization instead they meet their needs by renting appropriate services from cloud and thus, lead to increasing organizational performance. In word, performance means state or quality of function. So, the organizational performance is a general structure which it refers to how organizational operations perform. Neely et al defined performance as a process of explaining the quality of effectiveness and efficiency for past measures which it was the most famous definition for performance. According to this definition, performance is divided into two components: first, efficiency which describes how organization uses resources in the production of services or products i.e. the relationship between the real and ideal combination of inputs to produce certain outputs; second, effectiveness which describes the degree of achieving to organizational goals (Neel et al, 2008). Performance is known as acceptability of results for internal and external clients who get products, services, information and decisions or functional events such as presentations and competitions. Organizational performance can be considered from many different aspects that this project is focused on three dimensions of customer, operational and financial. Given that most successful and large organizations in developed countries have turned toward using this technology, it seems that there is a dire need to move toward this direction in our country, too. So, data centers and equipment are provided by IT-based companies that organizations can use this technology and establish it. This project studies the significant relationship between the presence and use of the cloud technology and performance of organization from three dimensions of customer, operational and financial.

\section{Theoretical Framework of Research}

\subsection{Cloud Computing}

If we want to study the new generation of Web-based services which it is mentioned as "Cloud Computing" we would found that this part of technology has experienced enormous changes since 2010 (Yoonesian, 2014). Although many firms and organizations in the world have not been turned toward these services but it seems that moving toward this technology is inevitable in the near future (Maleki, 2014). In cloud computing technology, users can access to programs, storage spaces, processing and even application development platforms through various tools; such as PCs, laptops, cellphones and PDA, and also through services provided by cloud computing. So, resources are placed on the servers' side instead of users' side. Cloud computing services are in the form of Utility Computing; this means that customers' needed services will be offered in servers and its payments like other public utilities- electricity, water, telephone, etc. are based on the level of individuals' usage (Akbari \& Sargolzaii Javan, 2010). McKinsey's ${ }^{3}$ study showed that there are 22 separate definitions of cloud computing (Ya'qubi et al, 2014). Some of these definitions are presented in the following:

By the NIST ${ }^{4}$ definition, cloud computing is a model for having comprehensive and easy access; and according to the order of a set of configuration-able computing resources such as networks, servers, storing spaces, applications and services to provide service quickly and through doing the least work or without the need for intervention of service provider ${ }^{5}$. In other words, cloud computing is a model from sets of models available for sharing resources. Other computing models are grid computing, autonomic computing, mainframe, utility computing, and peer to peer computing (Maleki, 2014). Could computing is an approach which it offers a wide range of ICT services according to the demand and need of customer through public (Internet) and private networks or both of them by using ICT developments like virtualization and grid computing through virtual hardware and software (Sultan \& Sultan, 2012).

Cloud computing refers to the applications provided on the Internet and systemic hardware and software in the data centers (Armbrust et al, 2010). Jula et al (2014) consider cloud computing consists of five main features, along with two other features that they added them based on the literature review, with three spanning model and four deployment model (implementation). This part will discuss on the features and the following parts will mention to the implementing models from the perspectives of the authors.

1. On-demand Self-service: User can ask for one or more services at any time s/he needs them and s/he can pay by using "pay and go" method without the need to interact with people through online control panel.

2. Broad Network Access: Resources and services that were placed in regions of different vendors, in a cloud that it can be accessible from a wide variety of places and they can be provided by weak or strong unbalanced

\footnotetext{
${ }_{3}^{3}$ Global Management Consulting Firm

${ }^{4}$ National Institute of Standards and Technology (http://www.nist.gov/it//cloud/index.cfm)

${ }^{5}$ wWw.NIST.gov
} 
customers. Terms of "easy to access standardized mechanisms" and "universal accessibility" have been used to refer to these features.

3. Resource Pooling: Providing a set of behavior stimulating resources adopted from a single common source. In other words, the user is not aware and s/he does not need to know about the location of resource provider. This approach helps venders to provide several real or virtual resources in could dynamically.

4. Rapid Elasticity: Elasticity is another name for scalability; elasticity means the ability to scale up or down resources whenever needed. Users can ask for different services and resources as much as they need at any time. This feature is so admirable that Amazon is well-known as a cloud service vendor. One of the most popular usages of services is called EC2 ${ }^{6}$.

5. Measured Service: Various aspects of cloud should be controlled automatically; monitoring, optimization, and reporting at various levels of abstraction for both vendors and consumers.

6. Multi-Tenacity: This concept is the fifth feature of cloud that it is proposed by Cloud Security Alliance. Multitenacity means that it is essential to develop a model for the implementation of policy-based, segmentation, isolation, administrative, service levels and chargeback/ invoicing for categorizing different consumers.

7. Auditability and Certifiability: It is important to provide a report card for services and routes that may assess the degree of regulation and observed policy (Jule et al, 2014).

\subsection{Implementation Models for Cloud Computing}

$\mathrm{NIST}^{7}$ defines deployment models in four ways as following:

1. Public Cloud: Public cloud or external cloud describes cloud computing in its original meaning and tradition. Services are provided dynamically via the Internet and in small units from a third party supplier; and supplier multi-tenanted resources to users and based on the utility computing model similar to electricity and phone industry sends bill for users. This cloud is improvised for public use and it is an alternative for a large industrial group that its owner is an organization selling cloud services (Sonsinsky, 2011).

2. Community Cloud: It occurs where several organizations have the same needs and they seek to enjoy benefits of cloud computing by sharing infrastructure. This option is more expensive than the public cloud; since, the costs in community clouds are divided among fewer users than public clouds, but it brings higher levels of confidentiality, security and compliance with policies. "Gov Cloud" is an example of community cloud.

3. Hybrid Cloud: A hybrid cloud which consists of multiple internal and external providers is an appropriate choice for most commercial establishments. Combining several cloud services enables users that make easier the transition to public cloud by avoiding from issues such as compatibility with $\mathrm{PCl}$ DSSC's ${ }^{8}$ standards (Orenstein, 2010).

4. Private Cloud: It is infrastructure of could computing model which it has been created by an organization for its internal use. The main factor that separates private clouds from commercial public clouds is maintenance manner and place of cloud infrastructural hardware. Private cloud make possible more control on all levels of cloud implementing such as hardware, network, operating system, software. Another advantage is greater security of public clouds which it results from placement of equipment within the boundaries of the organization and absence of communication with outside world (Maleki, 2014; Jula et al, 2014).

\subsection{Organizational Performance}

Organization is a set of interactive processes that expected performance from them -executive operation of processes- is realized among different organizational units (Bayazi Tehranvand et al, 2009). Organizational performance is as one of the most important concepts of management studies and it is undoubtedly considered as the most important measure of success in commercial companies (Xeiri \& Rowshani, 2013). In any organization, achieving to expected goals and results need to define them clearly in a hierarchical and comprehensive way; as organization's performance, designing indices and criteria for measuring the performance periodically, the criteria for performance evaluation, designing improvement programs and continuous monitoring of activities needs to ensure from the realization of goals and revising them (lavari \& Zahedi, 2013).

\footnotetext{
${ }^{6}$ Elastic Compute Cloud

${ }^{7}$ National Institute of Standards and technology

${ }^{8}$ Payment Card Industry Data Security Standards Council
} 


\subsubsection{The significance of Evaluating the Performance}

In the current era, dramatic developments in management knowledge have made inevitable the existence of evaluation system; so that, it is considered the lack of evaluation system in the various aspects of organization including evaluating use of resources and facilities, personnel, objectives and strategies as one of the symptoms of organization disease (Tavalaaee, 2007). Continuous improvement in organizations' performance makes a great power of synergy that these could support development programs and make opportunities for organizational excellence. Continuous improvement of performance would not be possible without the following items: without considering and informing of level of progress and achieving to objectives; without identifying the challenges facing the organization; and without getting feedback and informing of formulated policies and identifying items that need serious improvement. All aforementioned are not possible without measurement and evaluation. Lord Kelvin, British physicists, said about the necessity of measurement that whenever you can measure what you are speaking about and express it in numbers, you know something about it; otherwise, your knowledge is of a meager and unsatisfactory kind and it will never get puberty.

He offers measurement of the necessity feedback performance in the following items:

1. By pursuing the level of progress towards the specified objectives will determine whether formulated policies have implemented successfully or not.

2. By measuring the expected organizational results and also by assessing and measuring employees' and customers' satisfaction will determine whether policies have formulated correctly or not.

3. Evaluating and measuring performance make possible to identify areas that management should pay more attention to them and help to identify opportunities and constraints.

4. Evaluating the performance will bring information for managers in management decisions making, since much of the information needed for management decision making are provided by evaluating and measuring performance system. Each attempt that is done to achieve success should have a framework and organizational performance improvement should be based on a process which it is called "performance cycle". Every organizational performance application should start from measuring performance and then evaluate it (Pakravan \& Xowbiari, 2015).

\subsubsection{Models and Paradigms of Performance Evaluation System}

Quantitative models such as productivity criterion with value-added approach, efficacy criterion with efficiency and effectiveness approach, and profitability criterion with performance auditing approach; and qualitative models such as descriptive and evaluative criterion with organization commitment and ethics approach and some other criteria are used in modern paradigms of performance evaluation. There are at least seven scales for evaluating the performance of an organization that they are not necessarily distinct from each other. These scales are effectiveness, efficiency, profit and profitability, interest and productivity, quality of work life, innovation and creativity and quality (Tavalaaee, 2007).

1. AHP9 Model: The basic principles of this model are as following principle of hierarchical tree, principle of development and determining priorities, principle of logical consistency of judgments. Decision making based on the AHP method has lots of advantages such as single understandable model, process repetition, consensus and integration of judgments, give and take between the constituent elements of options, desirable combination of options, analytical and systematic approach, not insisting on linear thinking, hierarchical structure and measuring the intangible items in formulating and determining priorities (Tavalaaee, 2007).

2. Quality Management System for ISO ${ }^{10}$ : Quality management system for ISO is not presented simply as a system for comprehensive evaluation. The system manages processes that affect quality and determines the requirement for this issue; so, all the requirements and needs should appropriately be met in order to get a license. Measuring the efficiency and effectiveness of processes is a requirement which it has been emphasized strongly in ISO (Ed.2000). According to this standard, all the processes in organization must be identifies systematically; and their effectiveness and efficiency should be measured, finally the analysis of these parameters must lead to improving the processes (Tavalaaee, 2007).

3. The Performance Pyramid: A clear relationship between performance indicators at different hierarchical levels of organization is one of the requirements of performance evaluation system; so that each of units attempts to achieve the same goals. The performance pyramid model is one of models that it includes the way of making

\footnotetext{
${ }_{9}^{9}$ Analytic Hierarchy Process

10 International Organization for Standardization
} 
this relationship. The purpose of the model is linking between organization strategy and its operations. The performance evaluation system includes four levels of objectives which it represents organization's effectiveness and its internal efficiency. In fact, this framework reveals the difference between the indices that focus on the outside of the organization's groups such as customer satisfaction, quality and delivery on time and internal business indices such as productivity, cycle time and dissipations (Tavalaaee, 2007).

4. BSC ${ }^{11}$ : It is one of the successful tools in implementing strategic plans of organization to achieve a new performance measurement system (Valmohammadi \& Firouze, 2010). BSC is used as one of the performance measurement systems and it is a set of criteria that it provides a comprehensive viewpoint for the excellence managers (Zanjirdar et al, 2010).

5. The Business Process: So far the hierarchical frameworks have been described. Also, there are other frameworks that encourage managers to pay more attention to the horizontal flow of materials and information in the organization. For example, the business process that is proposed by Bourne in 1996.

According to this model, inputs, processes, outputs and results of an organization for determining criteria and evaluating performance are as following:

- Inputs: skilled and motivated employees, customers' needs, raw materials, capital, etc.

- Processing System: certificate of products, production of products, delivery of products, etc.

- Outputs: products, services, financial results, etc.

- Results: meeting customers' needs, customers' satisfaction, etc.

Therefore, appropriate indices should be derived according to the areas described above in order to evaluate the organization performance. Ultimately, the model is located at one end of a continuum which it has drawn from frameworks focused on the hierarchy to process frameworks; however, this model is conceptually accepted and undoubtedly and it is a useful method to describe the difference between indicators of input, process, output and result. In other words, hierarchy is completely ignored in the model and this issue is its weakness (Tavalaaee, 2007).

6. Medori and Steeple's Framework: It is one of comprehensive and integrated frameworks for auditing and improving performance evaluation systems. This approach involves six related steps. As many other frameworks, its starting point is also defining organization strategy and its success factor (step one). In the next step, organization's strategic requirements are matched with six competitive priorities which they are quality, cost, flexibility, time, delivery on time and future growth. Then, selecting appropriate indices begins by using a checklist that it includes 105 indices with complete definitions (step three). After that, the existing performance evaluation system is auditing to identify the currently used indices of company (step four). In the next step, it will discussed on the matter that how indices apply actually and each index will described by eight components which are title, purpose, pattern, equation, numbers, source of information, responsibility and improvement (step five). The final step will address to periodic reviews of organization's performance evaluation system by feedback (step six) (Tavalaaee, 2007).

7. Analysis Method of Stockholders: Designing performance evaluation system begins with recognizing the objectives and strategies of organization and that is why BSC begins the designing performance evaluation system with the following question: "what are our shareholders' demands?". In fact, BSC implicitly assumes that only shareholders have influence on the organization's objectives and other stakeholders are not involved in setting objectives. In other words, the model ignores the impact of other stockholders on the organization (Tavalaaee, 2007).

8. MBO ${ }^{12}$ : Philosophy of MBO's emergence is that in evaluations of individuals, their performance is evaluated based on the level of achieving to the specified objectives rather than evaluating their specific features and behaviors. First, organization's macro-objectives are determined in MBO; and then, these macro-objectives turn into micro-objectives by negotiating with managers at different levels and ultimately employees; at the end, they spread to the same organization (Tavalaaee, 2007).

9. The EFQM ${ }^{13}$ Excellence Model: It is another measurement framework which it is used widely. EFQM is a nonprescriptive model that it consists of nine criteria. Five of these are "Enablers" and four are "Results" (Tavalaaee, 2007).

\footnotetext{
11 Balanced Scorecard

12 Management by Objectives

${ }^{13}$ European Foundation for Quality Management
} 


\section{Review of Literature}

1. Naqeian Fesharaki et al (2014) conducted a research entitled "Providing Architecture of Security Reference for Environment of Organization's Private Cloud Computing". According to authors, capabilities and attractions of emerging cloud computing technology has caused that organizations tend to create and enjoy cloud services. On the other hand, security risks of this environment are unknown for organizations and absence of security architecture has caused that organizations encountered with confusion in decisions.

2. Yoonesian (2014) conducted a study entitled "Design and Deployment of Tablet Oriented Portable Organization with Could Computing Support as Mobile Business Management Infrastructure". This study aims at determining the management knowledge in hospital and creating a mobile and portable hospital with the ability to work everywhere. This study describes a system and process that in addition to high speed and agility to hospital's activities, it can leads organizations to situations that Employees and members of the hospital be associated with their desktop computer and their work desk at all-time through studying different and transformational aspects of tablets' deployment in hospitals instead of desktops and laptops.

3. Garrison et al (2015) have conducted a research entitled "Effects of IT Capability and Delivery Model of Success in Cloud Computing and Performance of Company to Support Processes and Operations of Cloud". This study aims at evaluating the effect of relationship, management and technical IT-based capabilities in success of could computing and analyzing the effects of success in organizational performance with regard to processes and operations supported by could computing. This article is studied the complex relationship between IT capabilities and public, private and hybrid distribution models of cloud. Results showed that It capability is the most influential factor to facilitate the success of cloud compared to technical and management capabilities of IT.

4. Tsohou et al (2014) have done a study entitled "Public Administration of Innovation via Cloud Computing". Their research aims at identifying and analyzing the recommended solutions and challenges about administrating public affairs of innovation. Modern technologies such as the Federation of services and cloud computing can greatly help to provide e-government services through flexible and scalable systems. In addition, they can facilitate reducing costs and overcoming the division of public information.

5. Jula et al (2014) have conducted a research entitled "The Combination of Cloud Computing: A Systematic Literature Review". According to the authors, the increasing tendency of network services' users in using cloud computing encourages vendors of web services toward service provision that are different in terms of functional and non-functional properties (quality of service) and they offer them in one service pool.

\section{The Research Model}

This study aims at investigating the impact of cloud computing technology on the organizational performance. Cloud computing technology is the independent variable and organizational performance is the dependent variable which is measured by three dimensions of operational, customer and financial.

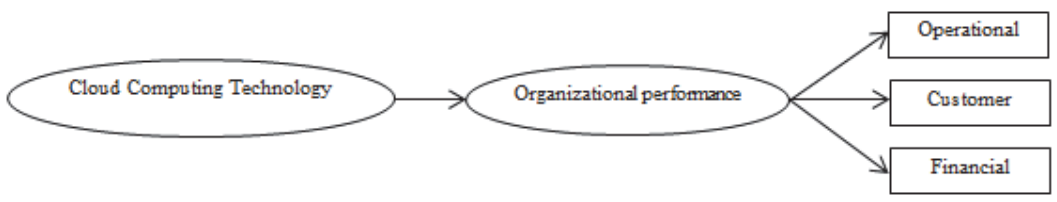

Independent variable

dependent variables

Figure 1: Research Model

\section{Objectives of the Study}

\subsection{The Main Objective:}

Studying the impact of cloud computing on the organizational performance 


\subsection{Secondary Objectives:}

1. Studying the impact of cloud computing on the financial performance of organization

2. Studying the impact of cloud computing on the customer performance of organization

3. Studying the impact of cloud computing on the operational performance of organization

\section{Research Methodology}

This study is done by cross-sectional and practical method. Population of this study consists of Zarin Iran porcelain Industries Company's experts which it was 80 persons. A standard questionnaire is research's measurement instrument which it has validity and reliability. According to the normality of data, parametric tests are used to analyze information by SPSS software.

\section{Findings}

\subsection{Descriptive Statistics}

Table 1: The Frequency of Device Type

\begin{tabular}{|c|c|c|}
\hline Frequency of Device Type & Percent & Cumulative Percentage \\
\hline Personal Computer & 37.0 & 37.0 \\
\hline Computer and Mobile & 44.4 & 81.5 \\
\hline Computer, Mobile and Tablet & 3.7 & 85.2 \\
\hline Mobile & 14.8 & 100.0 \\
\hline Total & 100 & \\
\hline
\end{tabular}

Table 2: The Frequency of Participants Based on the Age

\begin{tabular}{|c|c|c|}
\hline Variable & Percent & Cumulative Percentage \\
\hline $20-30$ & 40.7 & 43.1 \\
\hline $30-40$ & 44.4 & 90.2 \\
\hline Over 40 years & 9.3 & 100.0 \\
\hline Total & 94.4 & \\
\hline Lost & 5.6 & \\
\hline
\end{tabular}

Table 3: The Frequency of Participants Based on the Education Index

\begin{tabular}{|c|c|c|}
\hline Variable & Percent & Cumulative Percentage \\
\hline Master's Degree (MA) & 11.1 & 11.1 \\
\hline Bachelor's Degree (BA) & 59.3 & 70.4 \\
\hline Associate's Degree & 16.7 & 87.0 \\
\hline Diploma & 7.4 & 94.4 \\
\hline Total & 100.0 & \\
\hline
\end{tabular}

Table 4: The Frequency of Participants Based on the Organizational Position Index

\begin{tabular}{|c|c|c|c|}
\hline Organizational Position & Frequency Percentage & Valid Percentage & Cumulative Frequency \\
\hline Manager & 8.3 & 8.3 & 8.3 \\
\hline Assistant & 3.7 & 3.7 & 12 \\
\hline Master & 11 & 11 & 23 \\
\hline Expert & 45 & 45 & 68 \\
\hline Employee & 32 & 32 & 100 \\
\hline Total & 100 & 100 & \\
\hline
\end{tabular}


Table 5: The Frequency of Participants Based on the Work Experience

\begin{tabular}{|c|c|c|c|c|}
\hline \multicolumn{2}{|c|}{ Work Experience } & Frequency Percentage & Valid Percentage & Cumulative Frequency \\
\hline \multirow{4}{*}{ Valid } & $5-10$ & 22 & 22 & 22 \\
\cline { 2 - 5 } & $10-15$ & 42 & 42 & 64 \\
\cline { 2 - 5 } & Above 15 & 36 & 36 & 100 \\
\cline { 2 - 5 } & Total & 100 & 100 & \\
\hline
\end{tabular}

\subsection{Inferential Analysis}

Review of Research Hypotheses

\subsubsection{Hypothesis one: Cloud computing technology has significant impact on the financial performance of organization.}

Table 6: Cloud computing technology has significant impact on the financial performance of organization

\begin{tabular}{|c|c|c|c|c|c|}
\hline Index Title & Test Statistic & Significant Level & Mean & Lower Limit & Upper Limit \\
\hline Financial Performance & 12.93 & 0.00 & 4.20 & 1.01 & 1.39 \\
\hline
\end{tabular}

According to the table 6, value of financial performance is calculated equal to 12.93 . This value is presented positively which it shows that the index status is significantly different from the number 3 . The level of significance is calculated equal to 0.000 which it accepts hypothesis one. Mean index is equal to 4.20 which this value is more than 3 and it is at intermediate level. Now, lower and upper limits are used to examine the up or down status of the index. Given that lower and upper limits are positive, it can be said that most of them have verified the effectives of cloud computing on the financial dimension.

\subsubsection{Hypothesis Two: Cloud computing technology has significant impact on the customers' performance of organization.}

Table 7: Cloud computing technology has significant impact on the customers' performance of organization

\begin{tabular}{|c|c|c|c|c|c|}
\hline Index Title & Test Statistic & Significant Level & Mean & Lower Limit & Upper Limit \\
\hline Customers' Performance & 10.93 & 0.00 & 4.03 & 0.84 & 1.22 \\
\hline
\end{tabular}

According to the table 7 , value of customers' performance in test is equal to 10.93 . This value is presented positively which it demonstrates that the index status is significantly different from the number 3 . The level of significance is 0.000 which it accepts hypothesis one. Mean index is calculated equal to 4.03 which this value is more than 3 and it is at intermediate level. Now, lower and upper limits are used to examine the up or down status of the index. Given that lower and upper limits are positive, it can be said that most of them have verified the effectives of cloud computing on the financial dimension.

\subsubsection{Hypothesis Three: Cloud computing technology has significant impact on operational performance of organization.}

Table 8: Cloud computing technology has significant impact on the operational performance of organization

\begin{tabular}{|c|c|c|c|c|c|}
\hline Index Title & Test Statistic & Significant Level & Mean & Lower Limit & Upper Limit \\
\hline Operational Performance & 7.34 & 0.00 & 3.95 & 0.69 & 1.21 \\
\hline
\end{tabular}

According to the table 8, value of operational performance in test is equal to 7.34 . This value is presented positively which it suggests that the index status is significantly different from the number 3 . The level of significance is also 0.000 which it accepts hypothesis one. Mean index is calculated equal to 3.95 which this value is more than 3 and it is at intermediate level. Now, lower and upper limits are used to examine the up or down status of the index. Given that lower and upper limits are positive, so it can be said that most of subjects have confirmed the effectives of cloud computing on the financial dimension. 


\subsubsection{Hypothesis Four: Cloud computing technology has significant impact on the performance of organization.}

Table 9: Cloud computing technology has significant impact on the performance of organization

\begin{tabular}{|c|c|c|c|c|c|}
\hline Index Title & Test Statistic & Significant Level & Mean & Lower Limit & Upper Limit \\
\hline Performance & 22.8 & 0.00 & 99.3 & 12. & 89.1 \\
\hline
\end{tabular}

According to the table 9 , the value of performance in test statistics is calculated equal to 8.22 . This value is presented positively which it demonstrates that the status of index is significantly different from the number 3 . The level of significance is 0.000 which it accepts hypothesis one. Mean index is calculated equal to 3.99 which this value is more than 3 and it is at intermediate level. Now, lower and upper limits are used to examine the up or down status of the index. Given that lower and upper limits are positive, it can be said that most of subjects have confirmed the effectives of cloud computing on the performance dimension.

\section{Conclusions and Recommendations}

1. Results of main hypothesis showed that cloud computing technology has a significant impact on organizational performance; so, it can be concluded that performance of organization will promote by using cloud computing in the organization. In this regard, the following suggestions are offered:

- The use of cloud computing technology in the implementation of organizational processed and systems

- Identifying suppliers of cloud services

2. Results of hypothesis one showed that cloud computing has a significant impact on the financial performance of porcelain company; so, implementing cloud computing can be useful in this field and it will lead to improving the financial performance. Some suggestions are offered here:

- Outsourcing of technology systems on cloud providers can use to improve the financial performance and to decrease the support costs of technology sector.

- Costs of technology sector will decrease by using inter-organizational shared and virtual servers.

3. Results of hypothesis two showed that cloud computing technology has a significant impact on customers' performance. Cloud computing has shared a convenient model for universal access to the reservoir of computing resources which it can be provided and be available with the least management effort or service provider interaction and so quickly (Naqeian Fesharaki et al, 2014). This model provides users a quick and convenient access to the required computing resources via connecting to a web; it also reduces the concerns such as scalability, providing resources and flexibility in addition to saving costs. Cloud distribution provides highly scalable database for applications, ubiquitous network access, independent place for resources and rapid elasticity (Tsohou et al, 2014; IBM Corporation, 2012; Furht \& Escalante, 2010). Cloud computing is a network-based model for convenient and universal access to a set of configuration-able computing resources such as networks, servers, storing spaces, applications and services; so these can be provided quickly and with the least work and effort or the need to intervention of service provider. Therefore, customers' satisfaction will increase through appropriate and optimized implementation of cloud computing technology. In this regard, implementing an appropriate system of customer relationship is recommended.

Also, the following recommendations can be expressed:

- The use of cloud computing in speeding up the provisions of services to customers

- The use of modern technologies to make proper management of customers relationship with high quality and speed

4. Sub-hypothesis three revealed that cloud computing technology can be effective on the operational processes of porcelain Company. Could computing technology can enhance managers' monitoring of units by linking between units and various parts. Results of research showed that there is a significant relationship between cloud computing and the three dimensions of organization- operational, customers and financial-; the following suggestions are offered in this regard:

- Establishing an information access portal for employees in order to update internal information as well as continuous communication between employees of different units.

- Making user-friendly the entrance and exit process of information to facilitate programming and use of modern technologies. 


\section{References}

Akbari, M; Sargolzaee Javan, M. (2010). Cloud Computing. Amir Kabir University of Technology, Cloud Computing Research Center.

Tavalaaee, R. (2007). Modern Approaches toward Assessing Organizations' Performance. Journal of Police Human Development, JulyAugust 2007, V. 12, N. 12.

Xeiri, B; Rowshani, A. (2013). Investigating the Mediator Role of Marketing Capabilities in the Relationship between Strategic Orientation and Organizational Performance (Case Study: Bank Melli Iran), Researcher (Management), spring 2013, V.10, N.29, P. $97-113$.

Rahnavard, F. (2008). Factors Affecting the Performance of Public Sector Organizations, Journal of humanities and social sciences management, V. 8, N. 4, winter 2009, P. 77-100.

Zanjirdar, M et al. (2011). Comparison of Performance Measurement Systems and Analysis of BSC as a Modern Performance Measurement System, Commerce surveys, N.41, P. 35-46.

Maleki, Arezo. (2014). Cloud Computing; Advantages and Challenges, Vaya safety wares.

Naqeian Fesharaki, M et al. (2014). Providing Architecture of Security Reference for Environment of Organization's Private Cloud Computing, Scientific journal of security research, V. 13, N. 47, fall 2014, P. 91-113.

Valmohammadi, Ch \& Firouze, N. (2010). Evaluating Performance of Organization by using BSC Technique (Case Study), Researcher (Management), summer 2010, V. 7, N. 18, P. 72-87.

lavari, V \& Zahedi, Sh. (2013). Designing a Conceptual Model of Organizational Performance Management for Public and Private Organizations, strategic management thinking (management thinking), spring- summer 2013, V. 7, N. 1, P. 79-122.

Ya'qubi, N et al. (2014). Identification and Rating Key Factors Influencing on the Use of Cloud Computing in E-Health, Journal of Information Science and Technology, winter 2014, V. 30, N. 2, P. 549-572.

Yoonesian, Y. (2014). Design and Deployment of Tablet Oriented Portable Organization with Could Computing Support as Mobile Business Management Infrastructure, first telemedicine conference, AUT. 